\title{
The Impact of Goal Orientation, Self-Reflection and Personal Characteristics on the Acquisition of Oral Presentation Skills
}

\begin{abstract}
Although many educators help others to develop oral presentation skills, little research is available to direct the instructional design activities of these educators. In the present article an explorative study on university freshman is described, in which goal-setting, selfreflection, and several characteristics of the subjects during oral presentations were analysed. The research results emphasize the critical impact of motivational constructs, such as selfefficacy and goal orientation, next to the topic of the oral presentation on the acquisition of oral presentation skills.
\end{abstract}




\title{
The Impact of Goal Orientation, Self-Reflection and Personal Characteristics on the Acquisition of Oral Presentation Skills
}

\begin{abstract}
Abstrait
Bien que beaucoup d'éducateurs aident d'autres pour développer des qualifications orales de présentation, peu de recherche est disponible pour diriger les activités de conception d'instruction de ces éducateurs. Dans l'article une étude explorative des étudiants de première année d'université est décrite, dans laquelle 'goal-setting', 'self-reflection', et plusieurs caractéristiques des participants ont été analysés. Les résultats de la recherche soulignent l'impact critique des constructions de motivation, telles que 'self-efficacy' et 'goal orientation' en plus de la matière de la présentation orale.
\end{abstract}




\section{The Impact of Goal Orientation, Self-Reflection and Personal Characteristics on the Acquisition of Oral Presentation Skills}

\section{Introduction}

The importance of oral presentation skills is widely recognised. Many instructors at various educational levels ask their students to give oral presentations. Although the teaching of presentation skills is stressed in many curricula, it has hardly been researched empirically (Campbell, Mothersbaugh, Brammer \& Taylor, 2001).

The development of oral presentation skills is a time-consuming activity. This does not square very well with the current trend in higher education to reduce in-class instruction time. The latter increases the pressure to optimise the instructional environment and to adopt evidencebased approaches to direct instruction. [SPACING]

An important question in this optimalisation concerns the role the student can play: how can we help to make them more responsible for their learning with less input (=time) from the teacher?

A key element in the research on oral presentation skills acquisition is the need to understand the relationship between instructional environment variables, student characteristics, and their learning process and performance.

The available literature gives us a rather fragmented and limited picture of this relationship. A number of studies focus on assessment of oral presentations and construct evaluation instruments (Conor,2006), compare evaluation instruments (Carlson \& Smith-Howell, 1995; 
Edens, Rink \& Smilde, 2000) or study self and peer assessment of oral presentation skills (Campbell et al., 2001; Cheng \& Warren, 2005; Langan et al., 2005; Magin \& Helmore, 2001; Patri, 2002). Some authors concentrate rather on what we should teach about oral presentation skills and not on how we should teach it (e.g. Andeweg \& de Jong, 1998). Others try to deal with public speaking anxiety (e.g. Behnke \& Sawyer, 2000).

A few studies centre on the instructional process. Bourhis and Allen (1998) study the role of videotaped feedback; Jensen and Harris (1999) explore the use of a public speaking portfolio. Bayless (2004) researches the impact of placement, pace and preparation. Tucker and McCarthy (2001) investigate the role of service-learning and Calcich and Weilbaker (1992) studied the optimal number of in-class presentations. However research about the interaction of instruction with student characteristics is scarce and focuses mostly on the role of selfefficacy (e.g. Adams, 2004). Furthermore, no research is available focusing on predictors of oral presentation performance.

The literature is also limited when it comes to the development of a theoretical framework to guide the empirical research. In the following paragraphs we shall present a theoretical framework that incorporates a complex set of variables and processes which will be the focus of the present study. 


\section{Theoretical framework}

If we want the student to take charge of a greater part of the learning process, we enter the domain of self-regulated learning in which three cyclical phases are discerned: forethought, performance and self-reflection (Schunk, 2001; Zimmerman, 2000). A number of theoretical perspectives is available in this context. For this research we choose the social cognitive perspective of Bandura (Bandura, 1997; Schunk, 2001; Zimmerman, 2000) that builds on three interacting determinants of human functioning: environment, behaviour and person (see figure I).

\{Please insert Figure I about here\} FIGURE 1 IS A COMMON ILLUSTRATION AND NEEDS REFERENCING

Environment: Instructional environment

The central question concerning the environment is: can we foster self-regulated learning in the domain of oral presentation skills and what interventions can we design and implement to attain this objective? In the literature there are several instances of experiments involving goals and self-reflection, as these are essential elements in the phases before and after performance (Schunk, 2001; Zimmerman, 2000) and so we decided to use them in our experiment as well.

Marzano, Pickering and Pollock (2001) state that instructional goals narrow what students focus on. In addition, Locke and Latham (2002) stress three more specific mechanisms: goals perform an energizing function, goals affect persistence and goals affect action indirectly by 
arousal/discovery/use of task-relevant knowledge and strategies. Considering the importance of goals, the next question is: which goals must be chosen? Schunk (2001) summarizes research evidence that supports the benefits of specific goals, as they are more likely to enhance self regulation as compared to general goals. Bandura (1997) explains the efficacypromoting effect of sub-goals in contrast to general goals: when progress is measured against a short-term sub-goal it will promote a growing sense of efficacy, but when evaluated against a big and long-term goal, it can be experienced as being rather disappointing.

In relation to goal-setting, there is some controversy as to who is expected to set the goals. Ames (1992 posits that perception of control is a significant factor affecting learning and quality of learning. However the research literature is not univocal: when people accept and commit themselves to assigned goals, they can be equally well motivating as self-set goals (Schunk, 2001b). This discussion is of interest for the present study where students in the goal setting condition were put in two experimental conditions.

Self-Reflection is a critical element in the model of self regulation (Boekaerts et al., 2000; Pintrich \& Schunk, 2002) and considered to be crucial for future motivation and performance. Self-reflection is one of the three phases of self-regulation: forethought, performance and selfreflection, and composed of the two processes of self-judgment and self-reactions (Zimmerman, 2000). Reflecting is a meta-cognitive activity which includes evaluation of effort, time-allocation, strategies and learning aids (Masui \& Decorte, 2005).

These activities influence subsequent forethought and prepare the learner for further efforts (Zimmerman, 1998). Schunk and Ertmer (2000) recommend that intervention studies be conducted and more research attention devoted to the effectiveness of self-reflection. Building 
on the theoretical importance of self-reflection, our study will integrate reflective activities in an experimental intervention.

\section{Person: Student characteristics}

A basic assumption of the social-cognitive framework is that behaviour is influenced by a combination of environmental factors and personal characteristics (Urdan \& Schoenfelder, 2006). Applying this to the context of our study, this implies that oral presentationperformance is the result of the interaction of specific instructional interventions and student characteristics. Vermetten, Lodewijks and Vermunt (2002) suggest that a person's habitual way of learning and his learning conceptions influence his interpretation of the intervention. In this context Elen and Lowyck (1998) put great emphasis on knowledge about the learning potential of the instruction as another element that influences the interpretation. They labelled these conceptions about the learning process, the task and the environment the instructional meta-cognitive knowledge (Könings, Brand-Gruwel \& Van Merriënboer, 2005).

Conceptions or ideas and beliefs about learning have an impact on goal setting, learning activities and performance (Bakx, Vermetten \& Van der Sanden, 2003; Diseth \& Martinsen, 2003). Since learning conceptions are to a certain degree context-dependent, it is relevant to take the knowledge domain into account when studying learning conceptions (Bakx, Van der Sanden, Sijtsma, Croon \& Vermetten, 2006; Eklund, 1998; Vermunt \& Vermetten, 2004).

Pintrich (2003) has emphasized the central role of motivation when investigating learning and teaching. Motivation is the process whereby goal-directed activity is instigated and sustained 
(Pintrich \& Schunk, 2002). However in the literature many definitions and conceptualisations of motivation are found. Linnenbrink and Pintrich (2002) subdivide the motivational constructs found in the literature into four families of motivational beliefs: self efficacy, attributions, intrinsic motivation and goal orientations. Later on, Pintrich (2003) expanded the set of families of social-cognitive motivational constructs by adding task-value. Below, the five constructs and their interrelationships will briefly be described.

I. Bandura (1997, p.3) has defined self-efficacy as: "beliefs in one's capabilities to organize and execute the courses of action required to produce given attainments". The self-efficacy theory of Bandura $(1997,1998)$ is often used in literature. Correlational- and experimental studies show that students with a positive self-efficacy are more likely to work harder, attain higher scores on persistence and higher achievement levels (Linnenbrink \& Pintrich, 2002). A limited number of studies report negative effects of self-efficacy on performance, due to overconfidence (Vancouver, Thompson, Tischner, \& Putka, 2002). Self-efficacy beliefs vary in level, strength and generality (Pajares, 2002). Holloday and Quinoñes (2003) suggest that level and strength are a single factor of self-efficacy.

II. The attribution theory emphasizes that students will analyse failure or success experiences to determine the perceived causes. These perceived causes will impact on the expectations about future success (Eccles \& Wigfield, 2002).

III. Intrinsic motivation is the internal motivation to engage in an activity (Linnenbrink \& Pintrich, 2002). The literature demonstrates that intrinsic motivation promotes learning and achievement to a higher degree than extrinsic motivation (Pintrich \& Schunk, 2002).

IV. Goal theory emphasizes the goal orientations of individuals when receiving tasks (Linnenbrink \& Pintrich, 2002). In general, two goal orientations are distinguished: mastery (focused on learning and mastery of the content) and performance (focused on 
demonstrating ability) (Pintrich \& Schunk, 2002). Recently, a second dimension has been added to goal-orientation (Pintrich, 2003) by the introduction of a distinction between goal avoidance and goal approach.

V. The last construct, task-value, consists of four components (Eccles \& Wigfield, 2002): attainment value (personal importance of doing well on the task), intrinsic value (similar to intrinsic motivation), utility value (how well a task relates to current and future goals) and cost (negative aspects of engaging in a task).

The expectancy value theory incorporates these five constructs (Bruinsma, 2004; Eccles \& Wigfield 2002; Pintrich \& De Groot 1990; Pintrich \& Schunk, 2002). Expectancy is related to the question 'can I do this task' and the self-efficacy construct. Often this is influenced by the person's attributions. The value component can be interpreted as an answer to the question 'why am I doing this' (Pintrich \& De Groot, 1990) and deals with the goals, intrinsic motivation and task value.

\section{Behaviour: Student learning process and presentation performance}

Indicators of the variable 'behaviour' are the student learning process when developing the presentation skills and his/her final oral presentation. Observable indicators are time spent on the preparation of the presentation, notes of the presentation, consultation of others, practicing, and the presentation itself.

Building on the theoretical base described above, we defined in a better way our expectations of the impact of an experimental intervention on the development of oral presentation skills and to put forward concrete hypotheses about the impact of student characteristics. 


\section{Research hypotheses}

The following hypotheses are put forward.

1. The instructional components specific goals and self-reflection are positively related to the development of oral presentation skills:

a. Students in an experimental condition that fosters defining specific goals perform better as compared to students in a control condition where only a general goal has been presented by the instructor.

b. Students in an experimental condition that stimulates self-reflection perform better than students in a control condition.

2. Goal setting, self-reflection and specific student characteristics are significant predictors of oral presentation skills.

\section{Research design and data collection procedure}

\section{$\underline{\text { Participants }}$}

The participants were university freshman enrolled for a Psychology course as part of a bachelor degree in Business Administration. Part of this course focuses on the development of oral presentation skills. Students were expected to develop and give three oral presentations. Informed consent was obtained from 101 students ( 70 males; 31 females). These students also completed two questionnaires. 


\section{$\underline{\text { Research instruments }}$}

The questionnaires focused on a variety of student characteristics and background information as described in the theoretical section. Specific instruments were developed to assess the quality of the oral presentations.

\section{Student characteristics}

\section{Goal orientation measure: PALS}

The PALS (Patterns of Adaptive Learning Survey) scale is a widely used and validated questionnaire (Day, Radosevich \& Chasteen, 2003; Midgley et al., 1998; Ross, Shannon, Salisbury-Glennon \& Guarino, 2002; Smith, Duda, Allen \& Hall, 2002). Smith et al. (2002) compared the PALS with two other measures of goal orientation. They developed a 16 item version based on the questionnaire developed by Midgley et al. (1998) and concluded that the three goal orientation instruments were valid.

The scale consists of three 5 or 6 item subscales that represent the three goal orientations (task goal, performance approach and performance avoidance).

In the present study, the PALS scale was selected because of the skills-orientation of this scale. The PALS was translated into Dutch following the parallel blind technique (Behling \& Law, 2000).

\section{Domain-specific learning conceptions}

Bakx et al.(2003, 2006) constructed and validated a scale to measure the learning conceptions of social work students in the communication knowledge domain. This questionnaire was adapted to the context of oral presentations. The scale contains 27 items that assess four 
learning conceptions: the constructivist, the text-based, the model-based and the pragmatic learning conception.

\section{Self-efficacy}

As self-efficacy beliefs vary in level, strength and generality (Pajares, 2002), the questionnaire incorporates items about different aspects of public speaking (e.g. keeping eyecontact/ controlling nerves) and different levels (can you speak to a group of 10, 25, 50, or 100 students). To assess the strength of their beliefs, a rating scale was used, ranging from 1 ( $I$ cannot do this at all) to 10 (I'm absolutely sure I can do this). The use of the word can is significant in the particular items since we measure a judgment of the students' capability and not a statement about the capacities they would like to have (Pajares, 2002).

Bandura (1997, p.14) gives an example about personal self-efficacy in public speaking to demonstrate how context-sensitive self-efficacy judgments can be: “ ... differ depending on the subject matter, whether the speech is extemporaneous or from notes, and the evaluative standards of the audiences to be addressed, to mention just a few conditional factors ..." But Pajares (2002) warns that the construct of self-efficacy can become irrelevant when the definition is too narrow. He cautions researchers not to reduce self-efficacy to an atomistic level.

The self-efficacy scale consists of 10 items that require the student to give a rating of 1 to 10 .

\section{The student learning process}

Participants were asked to rate characteristics of their learning process (for the three oralpresentations) and perceptions regarding their progress on a 5 point Likert scale.

- How extensive was your written preparation?

- How much time did you spend preparing the presentation (in minutes)? 
- How many times did you reflect on your preparation/ did you consult someone else and did you change your approach as a result of these interventions?

- What was important for you when preparing the presentation (12 alternatives)?

- Are you happy with the progress you have made?

- What was the role of the following attributions? (Two internal and three external attributions on a 7 point Likert scale were given).

\section{Assessment of oral presentation performance}

In the literature only a limited number of studies has been found (Carlson \& Smith-Howell 1995; Daly, Vangelisti \& Weber 1995) about a validated and reliable way to measure the quality of oral-presentation skills, but no generally accepted assessment instrument was found. A new instrument - based on a variety of existing instruments - was constructed. Six scales were tested in a pilot study by four experienced researchers. Five of these six scales were used in previous studies by Carlson and Smith-Howell (1995); Daly et al. (1995); Wiertzema and Jansen (2004). Carlson and Smith-Howell (1995) reported Chronbachs' alpha $.91, .83$ and .69 for the three scales they used, and Daly et al. (1995) reported Chronbachs' alpha of .81 .The four experts used the six scales to assess videotaped presentations. In addition, a semi-structured interview was organized with each of them. The interviews were analyzed in order to develop a new assessment instrument for oral presentations. The new instrument is based upon on a rubric approach. The latter presents the assessor with a description of levels of performance in relation to specific criteria to assess task-performance (Hafner \& Hafner, 2003). In the present study ten specific criteria were used that require the assessor to score on a 5- point scale: three content items, five delivery items and two overall items. The quality of visual aids and grammar was not judged with this instrument. 
In the literature opinions vary in relation to the role of gender effects on assessment of presentation performance. Hafner and Hafner (2003) report gender neutrality, but Edens et al. (2000) report a significant gender effect. The impact of gender was controlled for during data analysis. [MENTION HERE THAT THE IMPACT OF GENDER WAS CONTROLLED FOR DURING DATA ANALSYIS. OTHERWISE YOUR READER IS LEFT WONDERING WHAT YOU DID ABOUT IT AND DOESN'T FIND OUT UNTIL THE RESULTS SECTION]

\section{Research procedure}

Information about background characteristics of the students was gathered at the start of the academic year. In the psychology course, all students received a theoretical introduction about communication, effective non-verbal behaviour and oral presentations. At the start of the next phase students were randomly assigned to one of four experimental conditions following a $2 \times 2$ factorial design:

1. Presentation of a general presentation goal and no self-reflection

2. Presentation of a general presentation goal and self-reflection

3. Invoking personal specific presentation goal setting and no self-reflection

4. Invoking personal specific presentation goal setting and self-reflection

All sessions were monitored by the researcher and followed a strait scripted format. The introduction of a general goal was very brief and focused on the improvement of presentation skills. In the specific goal condition the researcher explained - at the start of every session that it is not possible to pay attention to all elements of an oral presentation and urged the students to select a specific and concrete set of objectives from of a larger list. 
The second experimental variable in this study is self-reflection. After looking at the video recording of their oral presentation, students were asked: "What was good in your presentation? What went wrong and why? What did you learn seeing the video-recording of your presentation and what does this mean for the preparation of the next presentation?" This intervention is based on the stimulated recall interview technique (Meijer, Zanting, \& Verloop, 2002). Students in research conditions without self-reflection were not asked this type of questions and/or stimulated to reflect on their performance.

In each research condition, the students participated in three sessions, resulting in an individual three-minute presentation. Each presentation was videotaped. The experimental conditions were standardised as to place, duration, physical setting, facilities, and the session coordinator.

Immediately after their last presentation, students were asked to fill out the second questionnaire (perceptions about the learning experience and self efficacy). All students received extensive feedback at the end of this last session. This included discussion of their progress as compared to the earlier presentations.

Due to logistic problems, group size did vary. Analysis reveals oral-presentation scores are not significantly related to group size. Control of the potential impact of the 'order' in which they gave their presentation indicates that there is no significant correlation between the order variable and the score for the oral- presentation.

Role of the assessors 
A group of six experienced faculty members (three male and three female and with a language education background) evaluated the quality of the first and third presentation. Assessors did not teach the students they had to assess. The assessors were also unaware of the research questions. They assessed the first and last presentation of each student without knowing the order in the presentations. In view of improving inter-rater reliability, at least one presentation was additionally assessed by a colleague.

\section{Topic of the oral-presentation}

In view of standardisation, participants were instructed to give a presentation about two prescribed topics:

A. Present to a public of pupils from the fourth year of secondary education what they can expect in the last two years of secondary education and what courses they can choose.

B. Explain to pupils of the last year of secondary education what it means to study for a bachelor degree in business administration.

Half of the students started with the topic A and ended with B. The other students started with B and ended with A. Assessors could not know whether they were assessing a first or a second presentation.

\section{Research results}

Student characteristics: descriptives and correlations. 
Table 1 gives an overview of descriptives and correlations of the research instruments. The reliability analysis shows that seven scales out of nine are sufficiently reliable $(\alpha>.70)$.

Only one of the three PALS subscales presents a problem due to a low Cronbach's alpha score $(\alpha=.623)$. The correlation between the performance approach scale and the performance avoidance scale $(r=.487, n=95, p<.001)$ is in line with review results in Ross et al. (2002).

When we compare the means of the three subscales in Table 1 with the means in the Manual (Midgley et al., 2000) or in Ross (2002), we see that our participants score higher on the Mastery subscale and lower on the two Performance scales.

For the domain specific learning conception scales only the pragmatic learning conception presents reliability problems. Cronbach's alpha scores for the other subscales are comparable to those reported by Bakx et al. $(2003,2006)$ and reflect high reliability.

Cronbach's alpha scores of the pre-test self- efficacy test $(\alpha=.880)$ and the post-test selfefficacy test $(\alpha=.890)$ are both high.

We can derive from Table 1 that there is a significant and positive correlation, as also reported by Bakx et al. (2003), between self-efficacy and the constructivistic learning conception. But, in contrast to our expectations there is no negative correlation between reproductive learning conceptions (model- or text-based) and self-efficacy (Bakx et al., 2003).

\{Please insert Table 1 about here 
The 200 oral presentations were evaluated by using a rubric as described earlier in this article. The scores given on the base of the rubric were analysed by means of a principal components analysis (Varimax rotation) resulting in a two factor solution. The two factors were found to be in line with theoretical expectations. The Content factor comprises loadings on the variables: introduction, structure, conclusion and the Delivery factor that pulls together loadings on the variables: eye-contact, vocal delivery, enthusiasm, and body-language. Three variables loaded in a balanced way on both components: professionalism, effectiveness, and contact with audience. ANOVA of the scoring results based on the variable 'assessor' shows that differences in scoring are not due to the person of the assessor $\left(F_{(5,97)}=.498, p=.777\right)$. When controlling for the impact of the variable gender, neither the variable gender of the assessor $\left(F_{(1,93)}=.471, p=.617\right)$ nor an interaction between the gender of the student and the gender of the assessor was significant $\left(F_{(1,93)}=1.946, p=.166\right)$.

\section{Hypothesis 1: The impact of the instructional intervention}

The global presentation skills (sum of the ten criteria) between the first and last presentation improved significantly for all the subjects $(\mathrm{p}<.001)$. In terms of effect size the difference is moderate $(d=.64)$. Participants scored significantly higher on most of the ten criteria, with the exception of vocal delivery $(t$-value $=-1.119, p=.266)$ and eye-contact $(t$-value $=-1.808$, $p=.074)$. The effect size of the criteria ranged from moderate $(d=.63)$ for the content criterion introduction to small $(d=.36)$ for the overall criterion effectiveness.

According to our hypothesis, students in a condition that fosters defining specific goals will outperform students in a condition where only a general goal has been presented by the instructor. A significant influence of the independent variable goal setting was observed 
$\left(F_{(1,96)}=4.534, p=.036\right)$. The effect size was moderate (partial eta squared $\left.=.045\right)$. A more detailed analysis reveals that the difference is found for two major components of the presentation: Content and Delivery. While the difference for the factor Content $(F(1,96)=$ $8.090, p=.005$ ) is significant with a moderate to strong effect size (partial eta squared $=$ $.078)$, there is no significant difference in relation to the factor Delivery $\left(F_{(1,96)}=1.068, p=\right.$ .304). The research results of the ANCOVA show that differences at the time of the first presentation did not impact differences in the final presentation.

According to the hypothesis, students in a condition that stimulates self-reflection were expected to outperform students in other conditions. The analysis results do not however confirm this expectation $(F(1,96)=1.320, p=.253)$.

Impact of the topic of the oral presentation

As explained before, the presentations focused on two different topics. The mean score for an oral presentation about university was higher than the average score for the high school topic. This topic effect was significant for the last presentation $\left(F_{(1,98)}=4.483, p=.037\right)$ partial eta squared $=0.44$, but not for the first $\left(F_{(1,99)}=2.129, p=.148\right)$.

Further analysis reveals that students who first presented the high school speech and ended with the university topic made a significant progress $(t=-5.715, p<.001)$. In terms of effect size the difference is strong $(\mathrm{d}=1.04)$. Students who started with the topic about university and ended with the high school topic also made progress but not in a significant way $(t=-$ $1.548, p=.128)$. 


\section{Hypothesis 2: Predictors of oral presentation performance}

A regression analysis with 'performance on the last presentation' as the dependent variable and the subscale scores student characteristics (see Table 1) as predictors (stepwise method) indicate that self-efficacy and the performance approach scale of the PALS were the best predictors of performance predicting $12,9 \%$ of the variance in scores $\left(F_{(2,75)}=6.693, p=\right.$ .002). In a next step, the measures from the perception of the learning process and the performance score for the first oral presentation were added to the analysis. Using the stepwise method a significant model emerged $\left(F_{(4,73)}=6960, p<.001 R_{a d j}^{2}=.236\right)$. Significant variables were (beta-scores): performance approach scale PALS .233 ( $p=.026)$, post-test self-efficacy $.319(\mathrm{p}=.003)$, subject of the last presentation $.292(\mathrm{p}=.006)$ and internal attributions of learning outcome $.233(\mathrm{p}=.024)$.

Self-efficacy - as expected - is to be considered as the most important predictor. Pre-test related efficacy beliefs are significant predictors of student performance at pre-test level, but not at post-test level. Post-test self-efficacy beliefs correlate with the performance on the first and on the second presentation. It is therefore possible that students adjusted their 'selfefficacy beliefs' after the first presentation experience.

\section{Challenges and limitations}

Though considerable efforts were made, it proved difficult to completely standardise the situation due to the authentic character of the environment. This implies that a number of 
variables and processes could not be controlled for in the present study. It was for example not possible to control questions asked by the students or prior experiences of students with oral presentations. The limited duration of the intervention can also play a role because the intervention was reduced to three hours.

\section{Discussion and conclusions}

The main goal of the present study was to measure the influence of different instructional variables expected to play a role in the development of oral presentation skills. Little attention is paid in the literature to theoretical and empirical studies focusing on this competency. This is a striking shortcoming giving the central role of this competency in most higher education curricula.

A theoretical framework was presented to develop and research a specific instructional intervention, with a strong focus on the hypothetical impact of goal setting and selfreflection. The empirical study required the design and/or selection of a number of specific research instruments. Central attention was paid in this context to the development of a reliable research instrument to assess oral presentation skills. This instrument is a useful starting point for future research that could focus on additional measures to support the reliability of the instrument when used by professionals and peers.

The present research is to be considered as a first exploration of a complex of interrelated variables that play a role in the acquisition of oral presentation skills. The results of the first 
study show that it is possible to develop an intervention that fosters these skills. A key starting point seems to be goal setting as a critical variable in this process.

The impact of the instructional intervention was especially clear for the factor 'content'. Most students improved in paying more attention to the presentation introduction and to repeating the major points of their presentation at the end of the session. Performance indicators, such as eye contact and vocal delivery proved harder to be influenced and/or changed during this short instructional intervention.

Fostering self-reflection did yet not result in significant differences, though it seems that feedback (stimulated recall) based on the video recording of their presentations, did stimulate students' self-reflection. Future research should reconsider this variable and focus in more detail on the nature of feedback.

The motivational constructs self-efficacy, achievement goal and attributions play a significant role as predicted, though further exploration of the nature of this impact is needed.

On the basis of the present research, the following advice can be given to educators. Instructional intentions should promote goal-setting by students. Educators should focus on performance approach goals and stimulate students to show their abilities for oral presentations. Secondly, initial instruction and further feedback should stress the role and importance of internal attribution of success. Third, self-efficacy is a significant variable to pay attention to. Interventions should try to promote the level of self-efficacy of the students. The unexpected impact of the topic of the oral presentation points at a potential interaction with motivational variables. Students may have considered the 'high school' topic as less challenging, thus invoking a lower level of enthusiasm and resulting in lower oral presentation scores. 
The results about the impact of perception of the learning environment are consistent with other research. Students do not always experience a learning environment as it was intended (Könings et al., 2005). More research is needed that pays attention to the student perception of the instructional process for oral presentation skills acquisition. This should guide educators to be cautious and attentive about the interpretation of instructional interventions by students. THIS FINAL PARAGRAPH IS WEAK BECAUSE IT DOES NOT RELATE SPECIFICALL TO ORAL PRESENTATIONS.

\section{References}

Adams, K. (2004). Modelling success: enhancing international postgraduate research students' self-efficacy for research seminar presentations. Higher Education Research and Development, 23(2), 115-130.

Ames, C. (1992). Classrooms: goals, structures, and student motivation. Journal of Educational Psychology, 84(3), 261-271.

Andeweg, B., \& de Jong, J. (1998). "May I have your attention” Exordial techniques in informative oral presentations. Technical Communication Quarterly. 7(3), 271-284.

Bakx, A., Vermetten, Y., \& Van der Sanden, J. (2003). Self-perceived competence, learning conceptions and preferred learning situations in the domain of communication. British Journal of Educational Psychology, 73, 223-245.

Bakx, A., Van der Sanden, J., Sijtsma, K., Croon, M., \& Vermetten, Y., (2006). The role of students' personality characteristics, self-perceived competence and learning conceptions in 
the acquisition and development of social communicative competence: A longitudinal study. Higher Education, 51, 71-104.

Bandura, A. (1997). Self efficacy: the exercise of control. New York: Freeman.

Bandura, A. (1998). Self-efficacy. In. H. Friedman (Ed). Encyclopaedia of mental health. San Diego: Academic Press. Retrieved June $6 \quad 2003$ from www.emory.edu/EDUCATION/mfp/BanEncy.html

Bayless, M. (2004). Change the placement, the pace, and the preparation for the oral presentation. Business Communication Quarterly, June, 222-225.

Behling, O., \& Law, K. (2000). Translating questionnaires and other research instruments: problems and solutions. Thousand Oaks: Sage.

Behnke R., \& Sawyer, C. (2000). Anticipatory anxiety patterns for male and female public speakers. Communication Education, 49 (2), 187-195.

Boekaerts, M., Pintrich P., \& Zeidner, M. (Eds.) (2000). Handbook of self-regulation. San Diego: Academic press.

Bourhis, J., \& Allen, M. 1998). The role of videotaped feedback in the instruction of public speaking: a quantitative synthesis of published empirical research. Communication Research Reports, 15(3), 256-261.

Bruinsma, M. (2004). Motivation, cognitive processing and achievement in higher education. Learning and Instruction, 14, 549-568.

Calcich, S., \& Weilbaker, D. (1992). Selecting the optimum number of in-class sales presentations. Marketing Education Review, 2, 31-33.

Campbell, K., Mothersbaugh, D., Brammer, C., \& Taylor, T. (2001). Peer versus self assessment of oral business presentation performance. Business Communication Quarterly, $64(3), 23-42$. 
Carlson, R., \& Smith-Howell, D. (1995). Classroom public speaking assessment: reliability and validity of selected evaluation instruments. Communication Education, 44, 87-97.

Cheng, W., \& Warren, M. (2005). Peer assessment of language proficiency. Language Testing, 22(1), 93-121.

Conor, C. (2006). Enhancing reflective learning through role-plays: the use of an effective sales presentation evaluation form in student role-plays. Marketing Education Review, 16(1), 9-13.

Daly, J., Vangelisti, A., \& Weber, D. (1995). Speech anxiety affects how people prepare speeches - a protocol analysis of the preparation processes of speakers. Communication Monographs. 62 (4), 383-397.

Day E., Radosevich, D., \& Chasteen, C. (2003). Construct- and criterion-related validity of four commonly used goal orientation instruments. Contemporary Educational Psychology 28 (4) $434-464$.

Diseth, A., \& Martinsen, O.(2003). Approaches to learning, cognitive style and motives as predictors of academic achievement. Educational Psychology, 23(2), 195-207.

Eccles,J., \& Wigfield, A. (2002). Motivational beliefs, values, and goals. Annual Review of Psychology. 53, 109-132.

Edens, F., Rink, F., \& Smilde, M. (2000) De studentenrechtbank : een evaluatieonderzoek naar beoordelingslijsten voor presentatievaardigheden. [Student court of justice: an evaluation of assessment instruments for presentation skills]. Tijdschrift voor Onderwijsresearch, [Journal for Educational Research], 24 (3-4), 265-274.

Eklund, G. (1998). Students' conceptions of learning in different educational contexts. Higher Education, 35, 299-316. 
Elen, J., \& Lowyck, J. (1998). Students' views on the efficiency of instruction: an exploratory survey of the instructional metacognitive knowledge of university freshmen. Higher Education, 36(2), 231-252.

Hafner, J., \& Hafner, P. (2003). Quantitative analysis of the rubric as an assessment tool: an empirical study of peer-group rating. International Journal of Science Education, 25(12), $1509-1528$.

Holladay, C., \& Quiñones, M. (2003). Research reports: practice variability and transfer of training: the role of self efficacy generality. Journal of Applied Psychology, 88 (6) 10941103.

Jensen, K., \& Harris, V. (1999). The public speaking portfolio. Communication Education, $48,211-227$.

Könings, K., Brand-Gruwel, S., \& Van Merriënboer, J. (2005). Towards more powerful learning environments through combining the perspectives of designers, teachers, and students. British Journal of Educational Psychology, 75, 645-660.

Langan, A., Wheater, C., Shaw, E., Haines, B., Cullen, W., Boyle, J., et al. (2005). Peer assessment of oral presentations: effects of student gender, university affiliation and participation in the development of assessment criteria. Assessment \& Evaluation in Higher Education, 30 (1), 21-34.

Linnenbrink, E., \& Pintrich,P. (2002). Motivation as an enabler for academic success. School Psychology Review, 31 (3), 313-327.

Locke E., \& Latham G. (2002). Building a practically useful theory of goal setting and task motivation- A 35 year odyssey. American Psychologist 57(9), 705-717.

Magin, D., \& Helmore P. (2001) Peer and teacher assessments of oral presentation skills: how reliable are they? Studies in Higher Education, 26(3), 287-298. 
Marzano, R., Pickering, \& D., Pollock, J. (2001). Classroom instruction that works. Research based strategies for increasing student achievement. Alexandria, Virginia, USA.: Association for Supervision and Curriculum Development.

Masui, C., \& De Corte, E. (2005). Learning to reflect and to attribute constructively as basic components of self-regulated learning. British Journal of Educational Psychology, 75, 351372.

Meijer, P., Zanting, A., \& Verloop, N. (2002). How can student teachers elicit experienced teachers' practical knowledge? Journal of Teacher education, 53(5), 406-419.

Midgley, C., Kaplan, A., Middleton, M., Maehr, M., Urdan, T., Anderman, L., et al. (1998). The development and validation of scales assessing students' achievement goal orientations. Contemporary Educational Psychology, 23(2), 113-131.

Midgley et al. (2000).Manual for the Patterns of Adaptive Learning Scales (PALS), retrieved May 17, 2006 from http://www.umich.edu/ pals/

Pajares, F. (2002) Self efficacy beliefs in academic contexts: an outline. Retrieved June 2, 2003 from http://www.emory.edu/EDUCATION/mfp/efftalk.html.

Patri, M. (2002) The influence of peer feedback on self and peer assessment of oral skills. Language Testing 19(2), 109-131.

Pintrich, P. (2003). A motivational science perspective on the role of student motivation in learning and teaching contexts. Journal of Educational Psychology 95 (4), 667-686.

Pintrich, P., \& De Groot, E. (1990). Motivational and self-regulated learning components of classroom academic performance. Journal of Educational Psychology, 82 (1), 33-40.

Pintrich, P., \& Schunk, D. (2002). Motivation in education. Theory, research and applications. $2^{\text {nd }}$ edition. New-Jersey: Pearson education. 
Ross, M., Shannon, D., Salisbury-Glennon,J., \& Guarino, A.(2002). The patterns of adaptive learning survey: a comparison across grade levels. Educational and Psychological Measurement, 62(3), 483-497.

Schunk, D. (2001a). Social cognitive theory and self-regulated learning. In B. Zimmerman, \& D. Schunk (Eds.). Self-regulated learning and academic achievement. Theoretical perspectives (pp.125-151). Mahwah, NJ: Lawrence Erlbaum.

Schunk,D. (2001b). Self-regulation through goal setting. ERIC:CASS Digest, 1-4.

Schunk, D.,\& Ertmer, P. (2000). Self-regulation and academic learning. Self-efficacy enhancing interventions. In M. Boekaerts, P. Pintrich, \& M. Zeidner ( Eds), Handbook of Self-Regulation (pp.631-649). San Diego: Academic Press.

Smith, M., Duda, J., Allen, J., \& Hall, H. (2002). Contemporary measures of approach and avoidance goals orientations: similarities and differences. British Journal of Educational Psychology, 72, 155-190.

Tucker, M., \& McCarthy, A. (2001). Presentation self efficacy: increasing communication skills through service-learning, Journal of Managerial Issues, 13(2), 227-244.

Urdan, T., \& Schoenfelder, E. (2006). Classroom effects on student motivation: goal structures, social relationships, and competence beliefs. Journal of School Psychology, 44(5), 331-349.

Vancouver, J., Thompson, C, Tischner, E., \& Putka, D. (2002). Two studies examining the negative effect of self-efficacy on performance. Journal of Applied Psychology, 87 (3), 506516.

Vermetten, Y., Lodewijks, H., \& Vermunt, J. (2002). Powerful learning environments? How university students differ in their response to instructional measures. Learning and Instruction, 12(3), 263-284. 
Vermunt, J., \& Vermetten, J. (2004). Patterns in student learning: relationships between strategies, conceptions of learning, and learning orientations, Educational Psychology Review, 16(4), 359-384.

Wiertzema, K. , \& Jansen, P. (2004). Spreken in het openbaar[Speaking in public]. Pearson education Benelux.

Zimmerman, B. (1998). Developing self-fulfilling cycles of academic regulation: an analysis of exemplary instructional models. In D. Schunk, \& B. Zimmerman ( Eds.), Self-regulated learning. From teaching to self-reflective practice. (pp.1-19). New York: The Guildford Press.

Zimmerman, B. (2000). Attaining self-regulation. A social cognitive perspective. In M. Boekaerts, P. Pintrich, \& M. Zeidner ( Eds), Handbook of Self-Regulation (pp.13-39). San Diego: Academic Press. 
Figure 1: Three determinants of human functioning (Bandura, 1997)

Environment

4

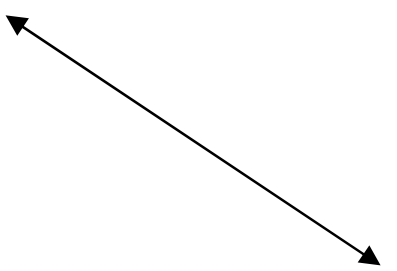

Behaviour

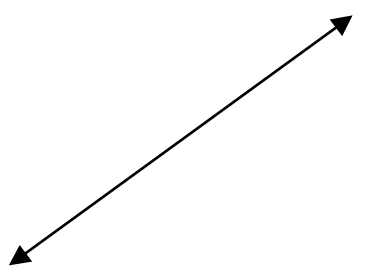

Person 
Table 1: Student characteristics: descriptives and correlations.

\begin{tabular}{|c|c|c|c|c|c|c|c|c|}
\hline & & & Std. & & & & & \\
\hline & Alpha & Mean & deviation & 3 & 4 & 5 & 8 & 9 \\
\hline $\begin{array}{l}1 \text { PALS taskgoal } \\
\text {. }\end{array}$ & .623 & 3,9604 & ,60267 & & & & & \\
\hline 2. PALS performance approach & .828 & 2,3526 & 90589 & $.487^{\star \star}$ & & & & \\
\hline 3. PALS performance avoid & .806 & 2,2896 & ,85136 & & $.274 * *$ & & & \\
\hline $\begin{array}{l}\text { 4..Model-based learning conception } \\
\text { (domain specific) }\end{array}$ & .753 & 2,7298 & ,65774 & & & $-.257^{*}$ & & \\
\hline $\begin{array}{l}\text { 5.Constructivistic learning } \\
\text { conception (domain specific) }\end{array}$ & .863 & 4,4050 & ,49846 & & & & $.235^{*}$ & $.300 * *$ \\
\hline $\begin{array}{l}\text { 6. Text-based learning conception } \\
\text { (domain specific) }\end{array}$ & .759 & 3,2367 & ,91661 & & & & & \\
\hline $\begin{array}{l}\text { 7.Pragmatic learning conception } \\
\text { (domain specific) }\end{array}$ & .624 & 3,8851 & ,46828 & & & & & \\
\hline 8.Pretest Self efficacy & .880 & 6,5860 & 1,37106 & & & & & $.667^{* *}$ \\
\hline 9.Posttest self efficacy & .890 & 6,5644 & 1,29233 & & & & & \\
\hline
\end{tabular}


